Article

\title{
Hydrothermal Synthesis of Ultra-Light Coal-Based Graphene Oxide Aerogel for Efficient Removal of Dyes from Aqueous Solutions
}

\author{
You Lv ${ }^{1}$, Baolin Xing ${ }^{1,2, * \mathbb{C}}$, Mingkun Zheng ${ }^{3}$, Guiyun $\mathrm{Yi}^{1}{ }^{1}$, Guangxu Huang ${ }^{1}$, \\ Chuanxiang Zhang ${ }^{1}$, Ruifu Yuan ${ }^{1}$, Zhengfei Chen ${ }^{4}$ (D) and Yijun Cao ${ }^{2, *}$ \\ 1 Henan Key Laboratory of Coal Green Conversion, College of Chemistry and Chemical Engineering, \\ Henan Polytechnic University, Jiaozuo 454003, China; lvyou0819@163.com (Y.L.); ygyun@hpu.edu.cn (G.Y.); \\ hgxu@hpu.edu.cn (G.H.); zcx223@hpu.edu.cn (C.Z.); yrf@hpu.edu.cn (R.Y.) \\ 2 Henan Province Industrial Technology Research Institute of Resources and Materials, Zhengzhou University, \\ Zhengzhou 450001, China \\ 3 School of Science, Hubei University of Technology, Wuhan 430068, China; zhengmingkun1993@163.com \\ 4 Graduate School of Energy Science, Kyoto University, Yoshida, Sakyo-ku, Kyoto 606-8501, Japan; \\ zhengfei.chen@gmail.com \\ * Correspondence: baolinxing@hpu.edu.cn (B.X.); yijuncao@126.com (Y.C.); Tel.: +86-0391-3986922 (B.X.); \\ $+86-371-67739808$ (Y.C.)
}

Received: 31 July 2018; Accepted: 27 August 2018; Published: 29 August 2018

\begin{abstract}
A novel carboxymethyl cellulose (CMC)-supported graphene oxide aerogel (CGOA) was fabricated from a cost-effective and abundant bituminous coal by a mild hydrothermal process and freeze-drying treatment. Such an aerogel has cross-linked graphene oxide layers supported by CMC, and therefore, displays high mechanical strength while having ultra-low density $\left(8.257 \mathrm{mg} \cdot \mathrm{cm}^{-3}\right)$. The CGOA has a 3D interconnected porous structure, beneficial graphene framework defects and abundant oxygen-containing functional groups, which offer favorable diffusion channels and effective adsorption sites for the transport and adsorption of dye molecules. The adsorption performance of rhodamine B by an optimized CGOA shows a maximum monolayer adsorption capacity of $312.50 \mathrm{mg} \cdot \mathrm{g}^{-1}$, as determined by Langmuir isotherm parameters. This CGOA exhibited a better adsorption efficiency $(99.99 \%)$ in alkaline solution, and satisfactory stability $(90.60 \%)$ after three cycles. In addition, adsorption experiments on various dyes have revealed that CGOA have better adsorption capacities for cationic dyes than anionic dyes.
\end{abstract}

Keywords: coal-based graphene oxide; aerogel; adsorption; dyes; carboxymethyl cellulose

\section{Introduction}

Water pollution has become one of the most urgent global environmental issues due to the rapid development of modern industry worldwide. Among a variety of water pollutions, dyes are the most common pollutants appearing in wastewater from the textile, printing, paper, cosmetics, feather, and leather industries [1-4]. Since most dyes do not biodegrade and have high toxicity (e.g., carcinogenic and mutagenic effects), the presence of dyes even at very low concentrations (less than $1 \mathrm{ppm}$ for some dyes) in water is highly visible and undesirable, and can lead to severe problems in human health [4-6]. Many techniques and processes have been applied for the treatment of dyes from wastewater, including photocatalytic degradation [7], membrane separation [8], chemical precipitation [9], biological oxidation [10], and adsorption [11]. Among these methods, adsorption is considered an effective and promising approach, because it has the advantages of low-cost, convenient 
operation, no secondary pollution, and recyclability $[12,13]$. Therefore, the exploitation of cost-effective adsorbents with high efficiency is an important focus in related research fields.

Graphene, as a new type of carbon nanomaterial with large specific surface area and excellent physical and chemical properties [14], has been widely used in adsorption for the waste water treatment [15-17] and biomedical fields [18-22]. Graphene oxide (GO) has similar properties to graphene, but is more hydrophilic because of a variety oxygen functional groups, which is a precondition as an adsorbent used in aqueous systems [23,24]. However, in the past few years, the potential toxicity of graphene/GO has attracted much attention from scholars in various fields $[25,26]$. The particulate state, surface functional groups, and oxygen content/surface charges of graphene/GO may significantly affect its toxicity in biological systems [27]. The application of GO aerogels has largely broken through the above limitations owing to its unique macrostructure with a block backbone and very low density for facile separation from aqueous solutions. In addition, GO aerogel has a highly active surface and large pore volume with three-dimensional (3D) interconnected porous structures, which can offer multi-dimensional adsorption active sites to ensure large adsorption capacity and desirable adsorption efficiency. Abundant hydrophilic polar groups such as hydroxyl, carboxyl, and epoxy groups distributed on the surface of carbon frameworks improve the affinity of GO aerogels to adsorbates in aqueous solution [28-32].

Several synthetic techniques, including self-assembly [33], bioassembly [34], unidirectional freezing [35], and ice crystal templating [32], have been developed to prepare GO aerogel for wastewater treatment. However, these GO aerogels with 3D architectures often suffer from poor mechanical strength, and are prone to collapses or even fragmentation upon immersion in water, which not only hinders the effective reutilization of the aerogel, but causes secondary pollution in water environments. In order to overcome this drawback, introducing various types of cellulose as reinforcement agents or cross-linking agents during the preparation process has been studied recently as a means to improve the mechanical strength and stability of the GO aerogel. Sun et al. used bamboo as the starting material to synthesize GO/cellulose aerogels for antibiotics removal by a one-step ultrasonication method under two conditions [36,37]. Tehrani et al. prepared composite hydrogel for cationic dye removal via sonicating GO and cellulose nanowhiskers in dimethylformamide, and continuously stirring at $110{ }^{\circ} \mathrm{C}$ for 2 days [38]. Wan et al. reported GO/cellulose hybrid aerogels prepared through a solution mixing-regeneration-freeze drying process [39]. Limited raw materials, toxic reagents, long production cycles and complicated preparation processes limit large-scale practical application, despite these composite materials exhibiting satisfactory adsorption capacities and structural stability. Therefore, it is highly desirable to develop a facile and cost-effective strategy to fabricate GO aerogel with a high adsorption capacity and excellent mechanical properties.

Carboxymethyl cellulose (CMC) is a water-soluble anionic linear polysaccharide derived from natural cellulose which is considered an inexpensive biocompatible material [40], and which usually contains large amounts of active functional groups including hydroxyl and carboxyl groups that act as desirable active sites during adsorption process [41]. In addition, the high specific surface area and abundant oxygen-containing functional groups of GO mean that they are easily functionalized by $\mathrm{CMC}$ due to the strong H-bond interaction between individual GO nanosheets and CMC [42]. Therefore, $\mathrm{CMC} / \mathrm{GO}$ composite materials have attracted attention as effective adsorbents for the removal of heavy metal ions and organic dyes from aqueous solution. Zhang Y. et al. prepared CMC/GO monoliths (GO, $0.2 \sim 5.0 \mathrm{wt} \%$ ) by a unidi-rectional freeze-drying method, and proved that the adsorption efficiency of multiple heavy metal ions was improved [43]. Liu J. et al. fabricated CMC/GO hydrogel microparticles (GO, 2 8 wt \%) via spray drying, and found that these hydrogel microparticles can effectively improve the adsorption capacity of dye molecules $\left(59 \mathrm{mg} \cdot \mathrm{g}^{-1}\right.$ for methylene blue and $66 \mathrm{mg} \cdot \mathrm{g}^{-1}$ for Eosin Y) [44]. Varaprasad K. et al. conducted preparation on dye removal CMC-Acrylamide-GO hydrogels (GO, 0.05 0.14 wt \%) by a free-radical polymerization method; the resulting maximum acid blue absorption capacity was $185.45 \mathrm{mg} \cdot \mathrm{g}^{-1}$ [45]. Although these methods have successfully synthesized various $3 \mathrm{D} \mathrm{CMC} / \mathrm{GO}$ composite materials, and the introduction of $\mathrm{GO}$ contributes significantly to the 
adsorption properties of the material, surprisingly, little attention has been devoted to the effects of a high quality proportion of graphene on the adsorption properties of materials.

In this work, GO is first obtained by a modified Hummers method using synthetic graphite derived from earth-abundant and low-cost bituminous coal as starting precursor. By comparison with conventional GO from natural graphite, coal-based graphene oxide (CGO) possesses higher porosity and larger surface area, because such synthetic graphite has relatively more structural defects and stronger binding forces among the neighboring graphite layers, which may provide more adsorption sites in the carbon matrix. Different contents of CMC are then incorporated into the CGO solution, and aerogels are prepared through a hydrothermal reaction coupled with freeze-drying. The microstructure and surface chemical state of the obtained final products were investigated through various characterization techniques. The adsorption behaviors of such a graphene oxide aerogel as an adsorbent were systematically evaluated by adsorption capacity, kinetic, isotherm, and thermodynamic for rhodamine $\mathrm{B}(\mathrm{RhB})$ in aqueous solution. Its dependence on other parameters such as solution $\mathrm{pH}$, regeneration performance, and different dyes were also investigated.

\section{Materials and Methods}

\subsection{Preparation of Coal-Based Graphene Oxide (CGO) and CGO Aerogel}

A high-rank bituminous coal derived from Shanxi Province, China was converted into synthetic graphite via high temperature graphitization treatment at $2800{ }^{\circ} \mathrm{C}$ for $2 \mathrm{~h}$. The relevant microstructure features of synthetic graphite can be seen in our previous work, and the degree of graphitization for this synthetic graphite was about 93.02\% [46]. Coal-based graphene oxide was prepared through a modified Hummers method using the coal-based synthetic graphite as the starting material. Here is a typical procedure: $1.5 \mathrm{~g}$ of coal-based synthetic graphite, $1.5 \mathrm{~g} \mathrm{NaNO}_{3}$, and $3 \mathrm{~g} \mathrm{KMnO}_{4}$ were added to $66 \mathrm{~mL}$ concentrated sulfuric acid $(98 \mathrm{wt} \%$ ) in sequence under ice bath with continuous stirring for $60 \mathrm{~min}$. Subsequently, the mixture suspension was transferred to $35^{\circ} \mathrm{C}$ water bath, maintained under stirring for $30 \mathrm{~min}$, and then slowly diluted by $132 \mathrm{~mL}$ deionized water, controlling the temperature at below $85^{\circ} \mathrm{C}$. Afterwards, about $5 \mathrm{~mL}$ of $\mathrm{H}_{2} \mathrm{O}_{2}(30 \mathrm{wt} \%)$ was added into the mixture suspension drop by drop until the appearance turned bright yellow. This yellow mixture was separated by centrifugation ( $8000 \mathrm{rpm}, 6 \mathrm{~min}$ ), and the remaining solid was subsequently washed with $5 \mathrm{wt} \%$ $\mathrm{HCl}$ solution and deionized water several times; then, the final resultant solid was ultrasonicated in deionized water for $75 \mathrm{~min}$ to obtain a coal-based grapheme oxide (denoted as CGO) suspension.

The CGO aerogels were synthesized through a one-step hydrothermal process, and subsequently freeze-dried. Firstly, $10 \mathrm{~mL} \mathrm{CGO} \mathrm{suspension}\left(3 \mathrm{mg} \cdot \mathrm{mL}^{-1}\right)$ was homogeneously mixed with a certain amount of carboxymethyl cellulose (CMC) and dispersed by ultrasonication for $30 \mathrm{~min}$; then, $40 \mu \mathrm{L}$ ethylenediamine (EDA) was added into the mixture solution and ultrasonic treatment was continuously carried out for $30 \mathrm{~min}$. The CGO/CMC/EDA mixture was transferred into a Teflon stainless steel reactor through hydrothermal treatment at $120{ }^{\circ} \mathrm{C}$ for $10 \mathrm{~h}$ to obtain CGO hydrogel. After that, the CGO aerogel was prepared by freeze-drying the hydrogel at $-70^{\circ} \mathrm{C}$ for $48 \mathrm{~h}$. The specific schematic illustration of the synthesis route for preparing CGO aerogel is shown in Figure 1. In terms of the different additive amounts of CMC, the prepared CGO aerogel was denoted as CGOA-X, where $\mathrm{X}$ represents the mass ratio of $\mathrm{CGO}$ to $\mathrm{CMC}$ in aerogel samples. 


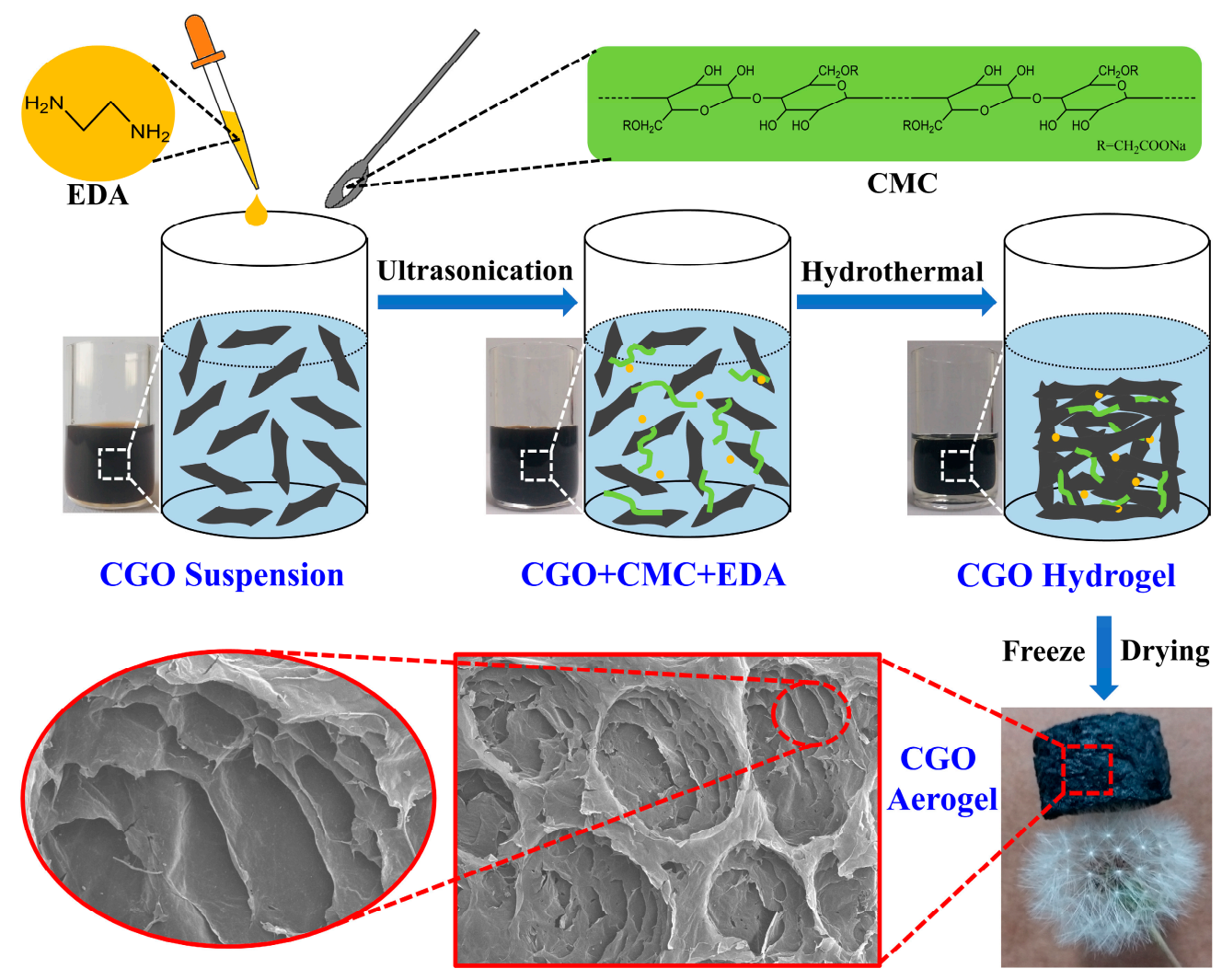

Figure 1. Schematic illustration of the synthesis route for preparing CGO aerogel.

\subsection{Characterization}

The surface morphology of CGO and CGOA were characterized by a Quanta FEG 250 field emission scanning electron microscope (SEM, FEI, Hillsboro, OR, USA). The surface of all samples was coated with gold prior to SEM observation. The X-ray diffraction (XRD) patterns were performed on a D8 advance diffractometer (Bruker, Karlsruhe, Germany) with $\mathrm{Cu} \mathrm{K} \alpha$ radiation source $(\lambda=0.15418 \mathrm{~nm})$, and patterns were recorded at $2 \theta$ in the range of $10-30^{\circ}$ with a scanning rate of $10^{\circ} \cdot \mathrm{min}^{-1}$. Raman spectrum of CGOA was recorded from $2000 \mathrm{~cm}^{-1}$ to $900 \mathrm{~cm}^{-1}$, using a inVia Raman spectroscope (Renishaw, London, UK) with $633 \mathrm{~nm}$ laser excitation at room temperature. The surface functional groups of samples were determined by Fourier transform infrared (FT-IR) spectroscopy using a Nicolet Nexus 470 FT-IR Spectrometer ranging (Thermo Fisher Scientific, Waltham, UK) from $4000 \mathrm{~cm}^{-1}$ to $400 \mathrm{~cm}^{-1}$. X-ray photoelectron spectroscopy (XPS) analyses were also carried out on an Escalab 250Xi (Thermo Fisher Scientific, Waltham, UK) photoelectron spectrometer at ambient temperature.

\subsection{Adsorption Experiments}

The adsorption behavior of CGOA- $X$ was studied by removing RhB under different conditions. A stock solution with a concentration of $1000 \mathrm{mg} \cdot \mathrm{L}^{-1}$ was prepared by dissolving $\mathrm{RhB}$ in deionized water, and the aqueous solutions of $\mathrm{RhB}$ were adjusted to different concentrations by diluting the stock solution. The $\mathrm{pH}$ of the solution was controlled by an appropriate concentration of $\mathrm{HCI}$ and $\mathrm{NaOH}$ solution. The residual concentration of $\mathrm{RhB}$ at different time intervals was determined using an UV5200 UV-visible spectrophotometer (Metash, Shanghai, China), and the measuring wavelength is $554 \mathrm{~nm}$. In addition, methyl orange (MO), crystal violet (CV), amido black (AB) and acid red (AR) were also used to evaluate the adsorption performances of CGOA-3 with the same method. All adsorption experiments were performed in a SHA-B temperature-controlled water bath shaker (Zhongda, Changzhou, China) at different temperatures using a glass flask and repeated twice to 
ensure the accuracy of the results. The adsorption capacity and adsorption efficiency calculated by the following equations:

$$
\begin{aligned}
& q_{e}=\left(C_{0}-C_{e}\right) V / m, \\
& q_{t}=\left(C_{0}-C_{t}\right) V / m, \\
& R_{e}=\left(C_{0}-C_{e}\right) / C_{0},
\end{aligned}
$$

where $q_{e}\left(\mathrm{mg} \cdot \mathrm{g}^{-1}\right)$ and $q_{t}\left(\mathrm{mg} \cdot \mathrm{g}^{-1}\right)$ are the adsorption capacity, $C_{0}\left(\mathrm{mg} \cdot \mathrm{L}^{-1}\right)$ and $C_{e}\left(\mathrm{mg} \cdot \mathrm{L}^{-1}\right)$ are the concentration of dyes before and after adsorption, $C_{t}\left(\mathrm{mg} \cdot \mathrm{L}^{-1}\right)$ is the concentration of dyes at time $t$, $V(\mathrm{~L})$ is the solution volume, $m(\mathrm{~g})$ is the mass of the adsorbent used and $R_{e}$ is the removal efficiency.

\section{Results and Discussion}

\subsection{Structural Characterization}

The structural stability and the recovery capacity of the adsorbent in water are necessary conditions for its practical application. Figure 2a is the photograph of CGOA-X $(X=0.5 \sim 4)$ after shaking in water for $5 \mathrm{~h}$. With the decrease of CMC content, the structural stability of CGOAs gradually declines, and the sample is shattered when the mass ratio of CGO to CMC is 4 . Therefore, the structure and property of CGOA-3 were systematically investigated. As can be seen in Figure $2 b$, the apparent density of the obtained CGOA-3 is only $8.257 \mathrm{mg} \cdot \mathrm{cm}^{-3}$, which is conducive to recovery in water. One CGOA-3 can support a weight more than 1700 times its own weight with little deformation, which further demonstrates the excellent structural stability of CGOA-3. From the SEM images, it can be seen that CGOA-3 has three-dimensional frameworks with randomly opened macroporous structures (Figure 2c,f), which may provide channels for the migration of dye molecules. At higher magnifications, the layers inside the aerogel are cross-linked to each other, rather than being arranged independently to one another (Figure $2 \mathrm{~d}, \mathrm{~g}$ ); additionally, the CMC is loaded onto the surface of CGO sheets during the hydrothermal process (Figure 2e), which is the reason why aerogel does not collapse during application. Moreover, it should be pointed out that the macropores of CGOA-3 can also be attributed to the sublimation of ice crystals during freeze-drying (Figure 2h) [47], resulting in an ultra-low density of aerogels.

The XRD patterns of GO, CMC, and CGOA composites were shown in Figure 3a. The interlayer spacing (d002) of CGO was calculated using Bragg's law to be about $0.76 \mathrm{~nm}$, corresponding to the diffraction peak at $11.6^{\circ}$. This value is obviously higher than the $0.34 \mathrm{~nm}$ for CG $\left(2 \theta=26.5^{\circ}\right)$, indicating the successful synthesis of CGO. Compared with CGO, the interlayer spacing (d002) of CGOA was reduced from 0.76 to $0.71 \mathrm{~nm}$, which is attributed to the partial reduction of the CGO sheet during the hydrothermal process by EDA. In addition, CMC shows a broad diffraction peak of its semi-crystalline structure at $19.9^{\circ}$, which suggests that crystallite sizes are very small [42]. After compounding with CGO, the intensity of the characteristic diffraction peaks of CGO and CMC in the composites was significantly weakened, which could be related to the strong interaction between CMC and CGO, resulting in a decrease in their crystallinity. 

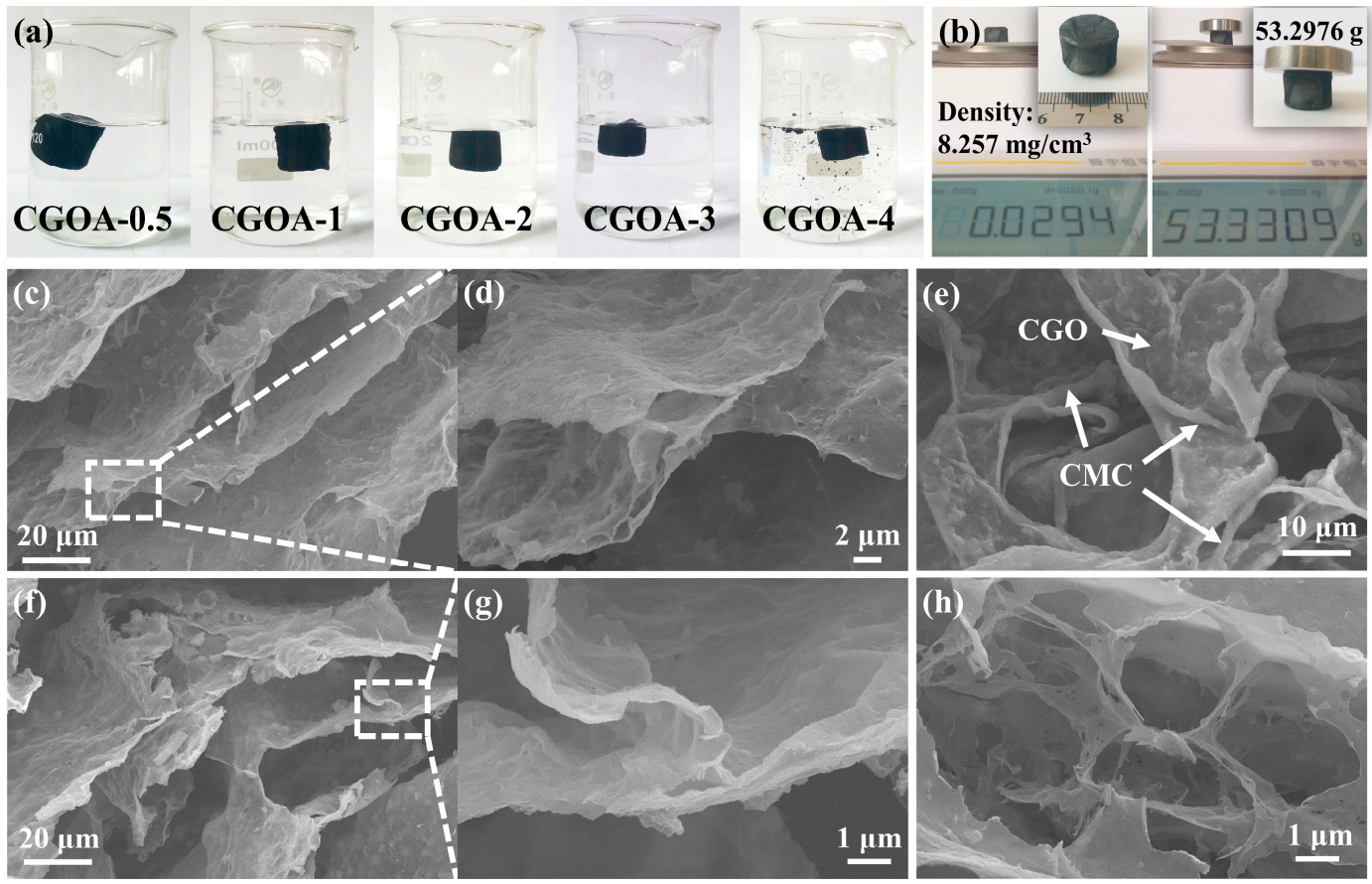

Figure 2. (a) Photograph of CGOA after shaking in water for 5 h; (b) Density and structural stability of CGOA-3; (c-h) SEM images of CGOA.

Raman spectroscopy is an effective technique for describing the degree of ordering and defects of carbon materials [48]. As can be seen from Figure 3b, both CGO and CGOA shows strong D and $\mathrm{G}$ bands, that can be assigned to the structural defects and the vibration of $\mathrm{sp}^{2}$-bonded in materials respectively [49]. Accordingly, the intensity ratio of the D-band to $G-b a n d\left(\mathrm{I}_{\mathrm{D}} / \mathrm{I}_{\mathrm{G}}\right)$ can be used for the determination of the degree of defects. Compared with traditional graphene oxide [40], a higher $\mathrm{I}_{\mathrm{D}} / \mathrm{I}_{\mathrm{G}}$ ratio (1.174) of CGO signifies a lower degree of ordering and more defects, which could undoubtedly provide more adsorption sites for dye molecules. After the hydrothermal reaction, the value of $I_{D} / I_{G}$ increased from 1.174 to 1.403 , probably because the surface of the two-dimensional sheet introduced more heteroatoms from CMC and grafted EDA molecules [47,50]. It should be noted that the G-band is usually shifted when the covalent structure is formed between the carbon material and other components [51]. Therefore, the shift of the G-band in CGOA implies the formation of a new covalent bond in the CGOA.
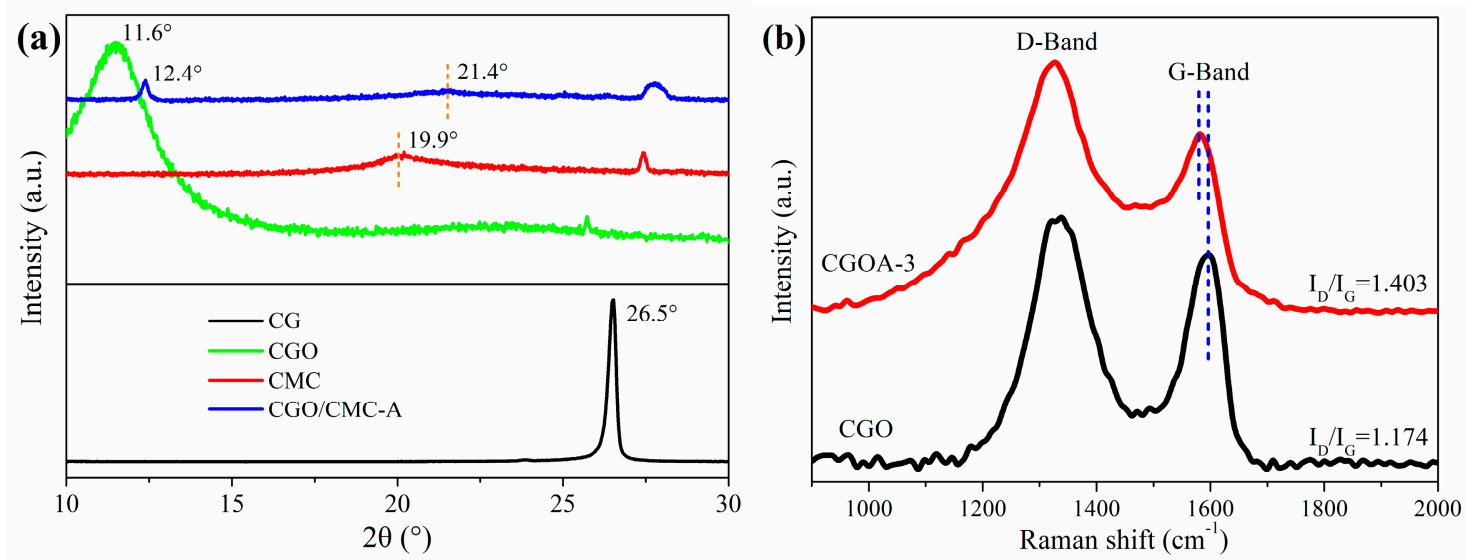

Figure 3. (a) XRD patterns of CG, CGO, CMC and CGOA; (b) Raman spectra of CGO and CGOA. 
To further understand the interaction between CMC and CGO, the FT-IR and XPS spectra of several samples are shown in Figure 4. From Figure $4 \mathrm{a}$, the chemical changes in CGOA-3 were investigated with FT-IR spectra before and after the fabrication. In CGO, some characteristic absorption bands appear at 3421, 1730, and $1624 \mathrm{~cm}^{-1}$, which represent the stretching vibration of $\mathrm{O}-\mathrm{H}, \mathrm{C}=\mathrm{O}$ and $C=C$, respectively [52]. From the spectra of $C M C$, peaks at 3441 and $1631 \mathrm{~cm}^{-1}$ could be ascribed to the stretching vibration of $\mathrm{O}-\mathrm{H}$ and symmetrical modes of carboxylate ions [40]. Compared with the CGO and CMC samples, there are several changes for the spectrum of the CGOA-3 sample, which sufficiently verify the strong interaction between CGO and CMC. The stretching vibration of $\mathrm{O}-\mathrm{H}$ blue shifts to $3433 \mathrm{~cm}^{-1}$, which indicates the formation of the composite is facilitated by $\mathrm{H}$-bonding interaction between CGO and CMC. On the other hand, the carbonyl stretch of carboxylate groups of CMC was overlapped with that of carboxylic groups of CGO at about $1577 \mathrm{~cm}^{-1}$, which is attributable to the interaction between the hydroxyl groups of CMC and the carboxyl groups of CGO [44,53]. In addition, it is worthwhile mentioning that the new peak at $1654 \mathrm{~cm}^{-1}$ is assigned to $-\mathrm{NH}(\mathrm{R})$ functional groups [54], suggesting that EDA produced a covalent bond during cross-linking with $\mathrm{CGO}$, in consistent with the Raman analysis.

The surface chemistry of CGO and CGOA were also characterized by XPS. From the comparative analysis in Figure $4 \mathrm{~b}$, it can be seen that peaks at $\sim 284.6 \mathrm{eV}, \sim 400 \mathrm{eV}$, and $\sim 532 \mathrm{eV}$ correspond to C1s, N1s and O1s spectrum, respectively [55]. Among them, the appearance of N1s peaks is ascribed to the cross-linking effect of nitrogen-containing groups (from EDA) with oxygen functional groups of CGO [33]. The C1s spectra can be deconvoluted into four different binding configurations, which include $\mathrm{C}-\mathrm{C}$ at about 284.6, $\mathrm{C}-\mathrm{NH}_{2}$ at about 285.4, $\mathrm{C}-\mathrm{O}$ at about 286.3 and $\mathrm{C}=\mathrm{O}$ at about $288.0 \mathrm{eV}$ [47]. Similarly, the N1s peak can be deconvoluted into two peaks in the forms of $\mathrm{NH}_{2}$ and $-\mathrm{NH}_{2} / \mathrm{NH}_{3}{ }^{+}$[56]. The various oxygen and nitrogen functionalities may endow the aerogel with enhancement of hydrophilicity and plenty of adsorption sites.
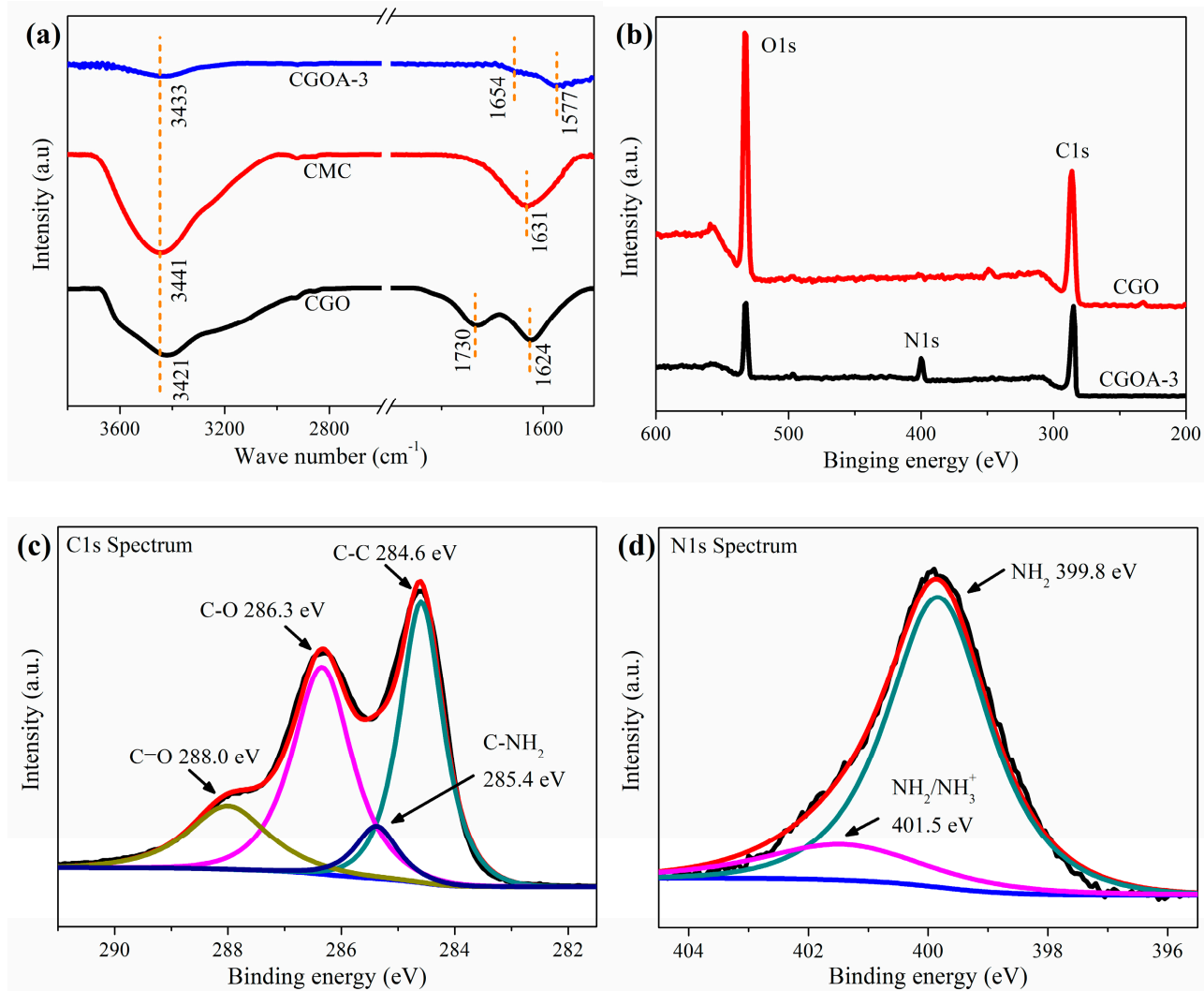

Figure 4. (a) FT-IR spectra of CGO, CMC and CGOA; (b) XPS spectra of CGO and CGOA; (c) Curve fit of $\mathrm{C} 1 \mathrm{~s}$ spectrum of CGOA; (d) Curve fit of N1s spectrum of CGOA. 


\subsection{Adsorption Performance}

To compare the adsorption performance of CGOA-X $(X=0.5 \sim 3)$, adsorption experiments were carried out by adding a block of CGOA-X (with the same GO mass, $30 \mathrm{mg}$ ) into $50 \mathrm{~mL}$ RhB solution with an initial concentration of $100 \mathrm{mg} \cdot \mathrm{L}^{-1}, \mathrm{pH}$ of 10.0 , and temperature of $303 \mathrm{~K}$. Figure 5a shows the effect of time on the adsorption capacity of CGOA-X. The adsorption capacity of all samples increased rapidly during the first $60 \mathrm{~min}$, and no obvious change was found after $120 \mathrm{~min}$. Moreover, the adsorption capacity of CGOA-X is gradually increased with decreasing the CMC content, and eventually reaches up to $212.0 \mathrm{mg} \cdot \mathrm{g}^{-1}$, which suggests the sample with more CGO possesses much higher adsorption capacity. This phenomenon indicates that the adsorption of RhB primarily occurs on the CGO sheets, and the CMC serves as linker to strengthen the stability of CGOA to maintain the 3D network structure. The UV-vis absorption spectra of RhB in presence of CGOA-3 are presented in Figure $5 \mathrm{~b}$. The absorption peak intensity for RhB at $554 \mathrm{~nm}$ (the amount of RhB) decreases sharply initially, and then more gently with increasing the absorption time; this is in good agreement with the results presented in Figure 5 a. In order to better understand the adsorption process of the dyes, the adsorption kinetic, isotherm, and thermodynamic characteristics of CGOA-3 have been further investigated.

The effects of the initial RhB concentration and temperature of the solution on the adsorption capacity were also investigated at $283 \mathrm{~K}, 303 \mathrm{~K}$, and $323 \mathrm{~K}$ for a given initial RhB concentration ranging from 80 to $140 \mathrm{mg} \cdot \mathrm{L}^{-1}$. Figure $5 \mathrm{c}$ indicates that the adsorption capacity of CGOA-3 not only increases with increasing concentration of $\mathrm{RhB}$, but also proportionally to temperature. Obviously, the increasing driving force derived from the concentration gradient of the RhB accelerates the diffusion of RhB on CGOA [57], and the adsorbent has more adsorption sites at higher temperatures [58].

Furthermore, the adsorption rate of the adsorbent is also an essential parameter to evaluate its adsorption performance. A $20 \mathrm{~mL}$ syringe loaded with a block of CGOA-3 was used to filter the $\mathrm{RhB}$ solution of $50 \mathrm{mg} \cdot \mathrm{L}^{-1}$ under continuous filtration, as shown in Figure $5 \mathrm{~d}$. After $45 \mathrm{~s}$, about $20 \mathrm{~mL}$ RhB solution was filtered through the CGOA-3, and the filtrate was collected. The maximum absorption spectrum of RhB disappeared (Figure 5e), indicating that CGOA can remove RhB rapidly and completely. 

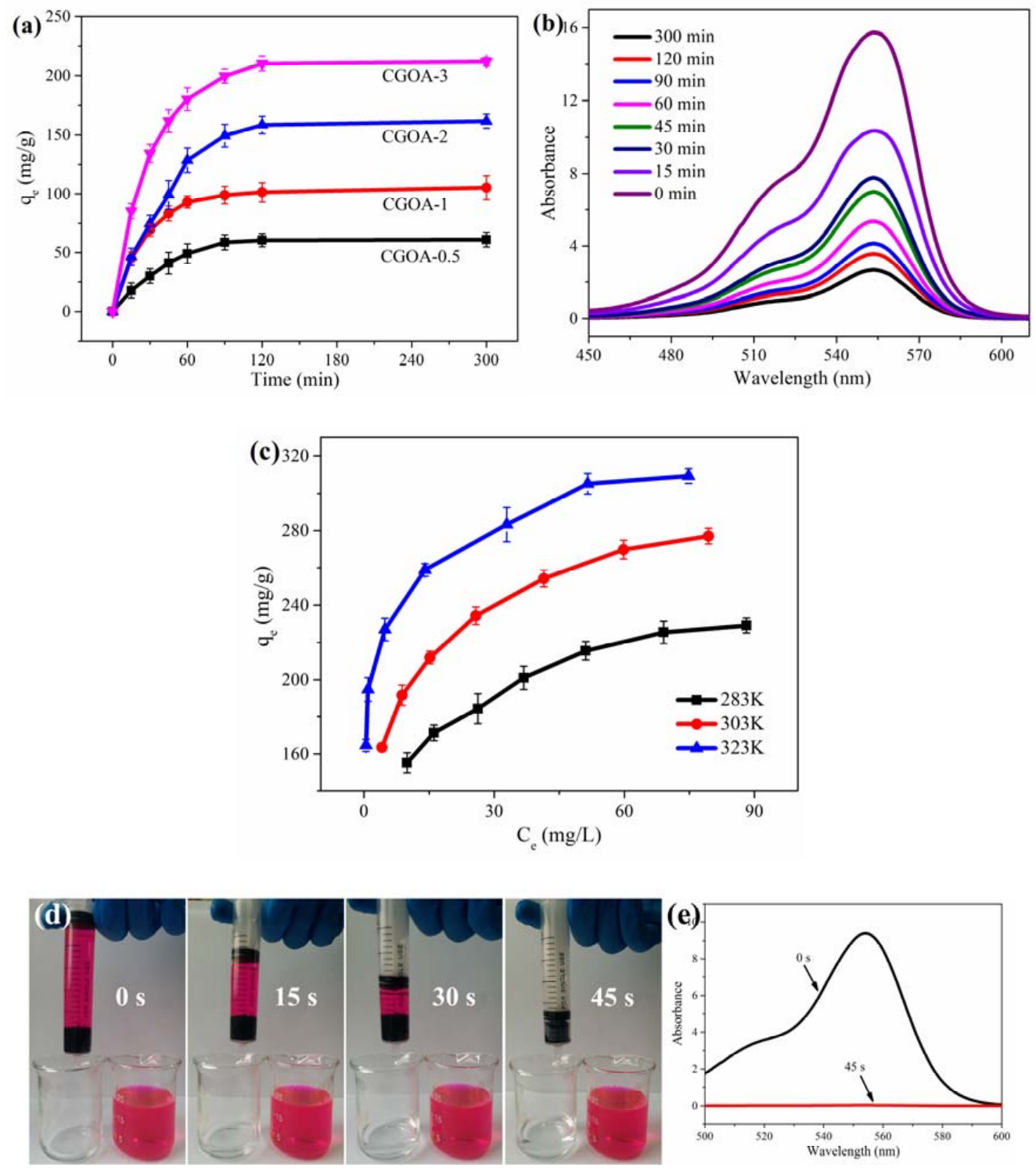

Figure 5. (a) Adsorption capacity of CGOA with different CMC content; (b) UV-vis spectra of RhB solutions treated with CGOA-3; (c) Effect of concentration and temperature; (d) Images of the solution before and after filtration; (e) UV absorption spectra of the solution before and after filtration.

\subsubsection{Adsorption Kinetics}

In order to predict the adsorption kinetics to $\mathrm{RhB}$, the pseudo first-order model and pseudo second-order model were applied for the experimental data. The pseudo-first-order kinetic model is expressed as [59]:

$$
\ln \left(q_{e}-q_{t}\right)=\ln q_{e}-k_{1} t
$$

where $q_{e}\left(\mathrm{mg} \cdot \mathrm{g}^{-1}\right)$ and $q_{t}\left(\mathrm{mg} \cdot \mathrm{g}^{-1}\right)$ are the adsorption capacities for RhB at equilibrium and at time $t$ (min), respectively, and $k_{1}\left(1 \cdot \mathrm{min}^{-1}\right)$ is the pseudo-first-order adsorption rate constant. In fact, the values of $q_{e}$ and $k_{1}$ can be obtained from the intercept and slope of the linear plot of $\ln \left(q_{e}-q_{t}\right)$ versus $t$ in Figure 6a.

The pseudo-second-order kinetic model is expressed as [60]:

$$
t / q_{t}=1 / k_{2} q_{e}^{2}+t / q_{e},
$$


where $k_{2}\left(\mathrm{~g} \cdot \mathrm{mg}^{-1} \mathrm{~min}^{-1}\right)$ is the pseudo-second-order adsorption rate constant. Similarly, the plot of $t / q_{t}$ versus $t$ may also yield the values of $q_{e}$ and $k_{2}$ in Figure $6 \mathrm{~b}$.

The corresponding kinetic parameters for adsorption of RhB onto the CGOA-3 are shown in Table 1. They show that the pseudo-second-order kinetic curve gives a better fit to the experimental kinetic data compared with the pseudo-first-order kinetic curve; this agreement is certified by higher $\mathrm{R}^{2}$ value in Table 1 . Moreover, the theoretical value of adsorption capacity determined by the pseudo-second-order kinetic equation is closer to the experimental value, suggesting that the pseudo-secondary adsorption model is suitable for adsorption kinetics of $\mathrm{RhB}$ on CGOA.
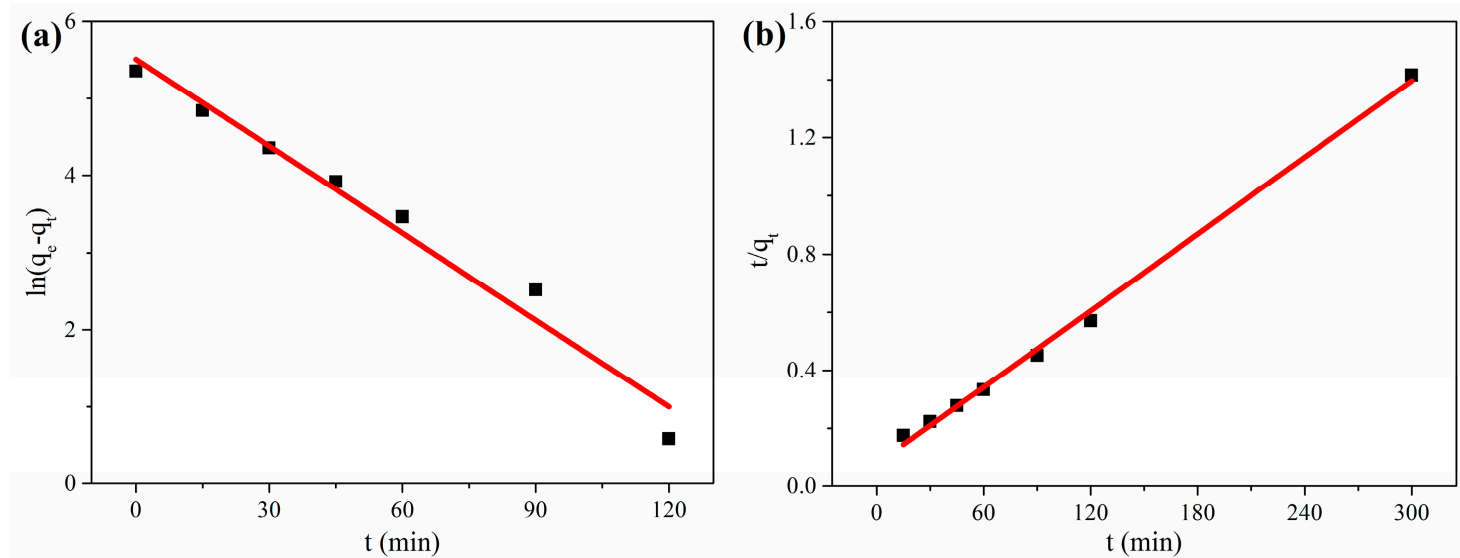

Figure 6. (a) Plots of $\ln \left(q_{e}-q_{t}\right)$ versus $t$ for the simulation of pseudo-first-order kinetics; (b) Plots of $t / q_{t}$ versus $t$ for the simulation of pseudo-second-order kinetics.

Table 1. Parameters of kinetic models.

\begin{tabular}{ccc}
\hline Kinetic & Parameters & Values \\
\hline \multirow{3}{*}{ Pseudo-first-order } & $q_{e}\left(\mathrm{mg} \cdot \mathrm{g}^{-1}\right)$ & 246.6894 \\
& $k_{1}$ & 0.0376 \\
& $R_{1}{ }^{2}$ & 0.9682 \\
\hline \multirow{3}{*}{ Pseudo-second-order } & $q_{e}\left(\mathrm{mg} \cdot \mathrm{g}^{-1}\right)$ & 227.7904 \\
& $k_{2}$ & 0.0002 \\
& $R_{2}{ }^{2}$ & 0.9964 \\
\hline
\end{tabular}

\subsubsection{Adsorption Isotherm}

Adsorption isotherm study is one of the most valuable methods to describe the mechanism of the adsorption for RhB, and is essential to predict the adsorption capacity. The Langmuir model assumes that adsorption is confined to a single layer over a homogenous surface with identical adsorption sites, and that there is no chemical reaction between the adsorbent molecules and RhB [61]. The Langmuir model equation can be expressed as:

$$
C_{e} / q_{e}=C_{e} / q_{\max }+\left(1 / q_{\max }\right) K_{L},
$$

where $q_{\max }\left(\mathrm{mg} \cdot \mathrm{g}^{-1}\right)$ is the maximum adsorption capacity, $C_{e}\left(\mathrm{mg} \cdot \mathrm{L}^{-1}\right)$ is the equilibrium concentration and $K_{L}\left(\mathrm{~L} \cdot \mathrm{mg}^{-1}\right)$ is the Langmuir constant, which is related to the affinity of the binding sites. A straight line with slope $1 / q_{\max }$ was obtained by plotting $C_{e} / q_{e}$ against $C_{e}$, as shown in Figure 7a.

For the Freundlich model, it assumes multilayer adsorption over a heterogeneous surface where adsorbed molecules are allowed to interact. The Freundlich model equation can be expressed as:

$$
\ln q_{e}=\ln K_{F}+\ln C_{e} / n,
$$


where $K_{F}$ and $1 / n$ are the Freundlich isotherm constant, and the adsorption intensity respectively, which can be obtained from the intercept and the slope of the linear plot of $\ln q_{e}$ versus $\ln C_{e}$, as shown in Figure $7 \mathrm{~b}$.

Table 2 shows the calculated coefficients obtained from Figure 7 and the Langmuir and Freundlich parameters. By comparing the values of the correlation coefficient $R^{2}$, the Langmuir model is more suitable for adsorption data than Freundlich, indicating that RhB adsorption in this system mainly occurred in a monolayer. The adsorption capacity is a pivotal parameter to judge the performance of an adsorbent. The maximum adsorption capacity ( $323 \mathrm{~K})$ of CGOA-3, as determined by the Langmuir model, is up to $312.50 \mathrm{mg} \cdot \mathrm{g}^{-1}$. It can be seen by comparison with other CMC/GO composite adsorbents in Table 3 that CGOA is a competitive adsorbent for dyes removal.
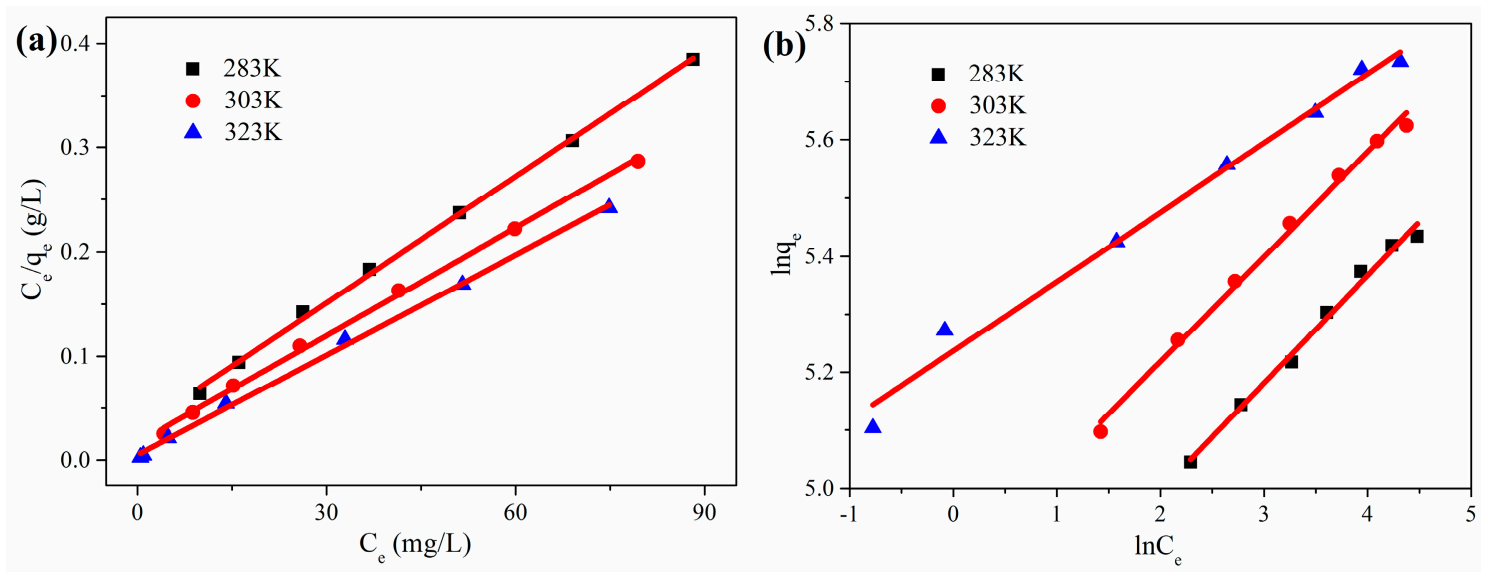

Figure 7. (a) Plots of $C_{e} / q_{e}$ versus $C_{e}$ for the simulation of Langmuir model; (b) Plots of $\ln q_{e}$ versus $\ln C_{e}$ for the simulation of Freundlich model.

Table 2. Parameters of Langmuir and Freundlich models.

\begin{tabular}{ccccccc}
\hline \multirow{2}{*}{$\mathbf{T}(\mathrm{K})$} & \multicolumn{3}{c}{ Langmuir } & \multicolumn{3}{c}{ Freundlich } \\
\cline { 2 - 7 } & $\boldsymbol{q}_{\max }$ & $\boldsymbol{K}_{\boldsymbol{L}}$ & $\boldsymbol{R}_{\boldsymbol{L}}{ }^{\mathbf{2}}$ & $\boldsymbol{K}_{\boldsymbol{F}}$ & $\boldsymbol{n}$ & $\boldsymbol{R}_{\boldsymbol{F}}{ }^{\mathbf{2}}$ \\
\hline 283 & 248.14 & 0.1332 & 0.9984 & 101.82 & 5.3783 & 0.9889 \\
303 & 291.55 & 0.2021 & 0.9981 & 128.73 & 5.5454 & 0.9938 \\
323 & 312.50 & 0.6275 & 0.9980 & 188.04 & 8.3843 & 0.9851 \\
\hline
\end{tabular}

Table 3. Comparison of saturated adsorption capacities of different adsorbents.

\begin{tabular}{cccc}
\hline Adsorbent & Dyes & $\boldsymbol{q}_{\max } \mathbf{( m g \cdot \mathbf { g } ^ { - \mathbf { 1 } } )}$ & References \\
\hline \multirow{2}{*}{ CMC/GO } & Methylene blue & 59 & {$[44]$} \\
& Eosin Y & 66 & {$[45]$} \\
CMC-AM-GO & Acid Blue-133 & 185.45 & This work \\
CGOA & Rhodamine B & 312.50 & \\
\hline
\end{tabular}

\subsubsection{Adsorption Thermodynamic}

Figure 8 shows that the adsorption capacity of RhB by CGOA has a certain relationship with temperature. To further evaluate the adsorption mechanism of CGOA, the thermodynamic parameters $(\Delta H, \Delta S$ and $\Delta G)$ are calculated from the following three equations [62]:

$$
\begin{gathered}
\ln \left(K_{L}\right)=-\Delta H / R T+\Delta S / R, \\
K_{L}=q_{e} / C_{e}
\end{gathered}
$$




$$
\Delta G=\Delta H-T \Delta S,
$$

where $K_{L}$ is the Langmuir equilibrium constant, $\Delta H\left(\mathrm{~kJ} \cdot \mathrm{mol}^{-1}\right), \Delta S\left(\mathrm{~J} \cdot \mathrm{mol}^{-1} \cdot \mathrm{K}^{-1}\right)$ and $\Delta G\left(\mathrm{~kJ} \cdot \mathrm{mol}^{-1}\right)$ are the enthalpy change, the entropy change and the change of Gibbs free energy, respectively, $R$ is the universal gas constant, and $T(K)$ is the solution kelvin temperature. Plotting $\ln \left(K_{L}\right)$ against $1 / T$ gives a straight line with slope and intercept equal to $-\Delta H / T$ and $\Delta S / R$, respectively.

The calculated values of thermodynamic parameters are reported in Table 4 . As the temperature rises, the value of $\Delta G$ decreases from -3.3833 to $-5.7753 \mathrm{~kJ} \cdot \mathrm{mol}^{-1}$, indicating that higher temperatures are beneficial to the adsorption process, and that the adsorption is a spontaneous process. Moreover, the positive value of $\Delta H$ indicated that the adsorption process was exothermic. The positive value of $\triangle S$ suggested a good affinity of $\mathrm{RhB}$ towards CGOA and increased randomness at the solid/solution interface during the adsorption process [63].

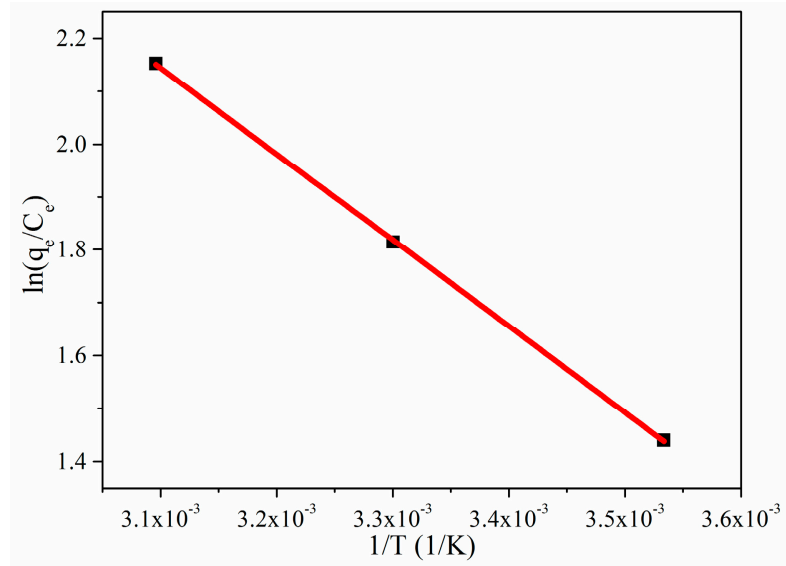

Figure 8. Plots of $\ln \left(K_{L}\right)$ versus $1 / \mathrm{T}$ for the simulation of thermodynamics.

Table 4. Parameters of thermodynamics.

\begin{tabular}{|c|c|c|c|c|}
\hline$T(\mathrm{~K})$ & $\Delta G\left(\mathrm{~kJ} \cdot \mathrm{mol}^{-1}\right)$ & $\Delta H\left(\mathrm{~kJ} \cdot \mathrm{mol}^{-1}\right)$ & $\Delta S\left(\mathrm{~J} \cdot \mathrm{mol}^{-1} \cdot \mathrm{K}^{-1}\right)$ & $R^{2}$ \\
\hline 283 & -3.3833 & & & \\
\hline 303 & -4.5793 & 13.540 & 59.780 & 0.9998 \\
\hline 323 & -5.7753 & & & \\
\hline
\end{tabular}

\subsubsection{Effect of $\mathrm{pH}, \mathrm{Cycles}$ and Different Dyes}

The $\mathrm{pH}$ of the solution is one of the important factors affecting the adsorption performance, which can affect the adsorption by changing the protonation of the functional group. The CGOA-3 was added into a $50 \mathrm{~mL}$ solution of different $\mathrm{pH}$, the $\mathrm{RhB}$ concentration was $50 \mathrm{mg} \cdot \mathrm{L}^{-1}$ and the temperature was $303 \mathrm{~K}$. Figure 9a shows the effect of $\mathrm{pH}$ values on the adsorption of $\mathrm{RhB}$ over the $\mathrm{pH}$ range of 2 10. As the $\mathrm{pH}$ of the solution increases, the adsorption curve of RB shows an upward trend. $\mathrm{RhB}$ is a cationic dye, but high concentrations of $\mathrm{H}^{+}$compete strongly with $\mathrm{RhB}$ molecules for adsorption sites in solution, which leads to a lower adsorption capacity. With the constant increase of $\mathrm{pH}$, the competition of $\mathrm{H}^{+}$gradually decreases, and the hydroxyl and carboxyl groups in CGOA will be deprotonated to form $-\mathrm{COO}^{-}$and $-\mathrm{O}^{-}$groups. Therefore, alkaline conditions can enhance the electrostatic attraction of $\mathrm{RhB}$ and $\mathrm{CGOA}$, and thus, have a higher adsorption capacity.

For the desorption study, the above CGOA-3 in RhB solution was collected by filtration, added to a $0.3 \mathrm{M} \mathrm{HCl}$ solution, and shaken for $5 \mathrm{~h}$. After that, the CGOA-3 was washed 5 times with $20 \%$ ethanol solution to remove residual $\mathrm{HCl}$. At last, the CGOA-3 was regenerated through freeze drying and reused for adsorption with the same conditions. After three cycles of adsorption-desorption, 
the adsorption efficiency is shown in Figure 9b. It can be clearly seen that CGOA retained $90.60 \%$ adsorption efficiency after three reuses.

$\mathrm{MO}, \mathrm{CV}, \mathrm{AB}$, and $\mathrm{AR}$ have been used in adsorption studies to further explore the adsorption capacity of CGOA for other dyes. The adsorption capacities for different dyes under the same conditions were shown in Figure 9c. Obviously, the adsorption efficiency for cationic dyes RhB (99.99\%), CV (99.99\%), and MO (87.40\%) are much higher than the anionic dyes AR (68.25\%) and AB $(31.78 \%)$. This phenomenon is caused by the strong electrostatic attraction between cationic groups in dyes molecules and the anionic groups of CGOA.
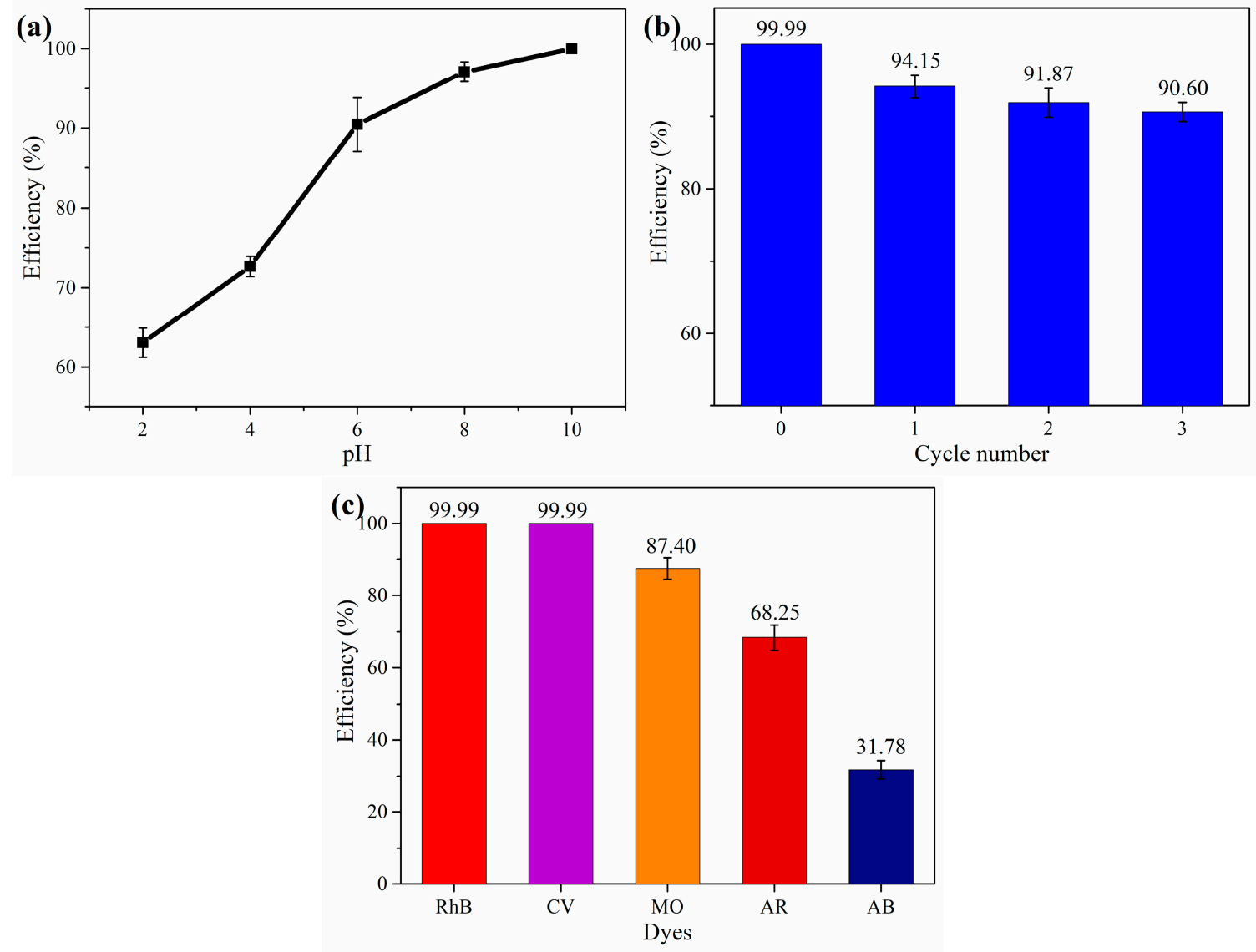

Figure 9. (a) Effect of the solution pH; (b) Recycling of CGOA; (c) Effect of different dyes.

\section{Conclusions}

Graphene oxide aerogel (CGOA) with high mechanical stability was successfully synthesized from bituminous coal and carboxymethyl cellulose by a mild hydrothermal treatment coupled with freeze-drying method. The prepared CGOA possesses a 3D interconnected network structure, beneficial graphene framework defect and abundant oxygen-containing functional groups. The adsorption of RhB molecules on CGOA occurs rapidly through electrostatic interactions. The adsorption kinetics was nicely fitted by the pseudo-second-order kinetic model, which indicates the adsorption rate is limited by the diffusion of RhB molecules onto the CGOA. The adsorption isotherm was best described by the Langmuir model and has a predicted maximum adsorption capacity of $321.50 \mathrm{mg} \cdot \mathrm{g}^{-1}$ at $323 \mathrm{~K}$. The thermodynamic analysis suggests that the adsorption of RhB by CGOA is spontaneous and endothermic. CGOA can be effectively regenerated and still retain more than $90 \%$ adsorption efficiency after three cycles. CGOA also demonstrated excellent adsorption capacities for cationic organic dyes investigated in this work, and further optimization of the type of materials for dye adsorption is currently underway. 
Author Contributions: Conceptualization and Methodology, Y.L. and B.X.; Investigation, Y.L. and M.Z.; Formal Analysis, G.Y., G.H. and R.Y.; Resources, C.Z.; Writing-Original Draft Preparation, Y.L. and B.X.; Writing-Review \& Editing, Z.C.; Project Administration and Funding Acquisition, Y.C.

Funding: This research was funded by the National Natural Science Foundation of China (51404098, U1361119, U1704146), China Postdoctoral Science Foundation (2017M620304), the Natural Science Foundation of Henan (162300410115) and the Education Department Science Foundation of Henan Province (19A440002, 19A530002).

Acknowledgments: This work was supported by the National Natural Science Foundation of China (51404098, U1361119, U1704146), China Postdoctoral Science Foundation (2017M620304) the Natural Science Foundation of Henan (162300410115) and the Education Department Science Foundation of Henan Province (19A440002, 19A530002).

Conflicts of Interest: The authors declare no conflict of interest.

\section{References}

1. Xiang, C.; Guo, R.; Lan, J.; Jiang, S.; Wang, C.; Du, Z.; Cheng, C. Self-assembling porous 3D titanium dioxide-reduced graphene oxide aerogel for the tunable absorption of oleic acid and rhodamineb dye. J. Alloy. Compd. 2017, 735, 246-252. [CrossRef]

2. Gupta, V.K.; Kumar, R.; Nayak, A.; Saleh, T.A.; Barakat, M.A. Adsorptive removal of dyes from aqueous solution onto carbon nanotubes: A review. Adv. Colloid Interface Sci. 2013, 24, 193-194. [CrossRef] [PubMed]

3. Xing, B.; Shi, C.; Zhang, C.; Yi, G.; Chen, L.; Guo, H.; Huang, G.; Cao, J. Preparation of TiO 2 /activated carbon composites for photocatalytic degradation of RhB under UV light irradiation. J. Nanomater. 2016, 2016, 3. [CrossRef]

4. Rafatullah, M.; Sulaiman, O.; Hashim, R.; Ahmad, A. Adsorption of methylene blue on low-cost adsorbents: A review. J. Hazard. Mater. 2010, 177, 70-80. [CrossRef] [PubMed]

5. Rachna, K.; Aggarwal, A.; Singh, N.B. Preparation and characterization of zinc ferrite-polyaniline nanocomposite for removal of rhodamine b dye from aqueous solution. Environ. Nanotechnol. Monit. Manag. 2018, 9, 154-163. [CrossRef]

6. Wang, X.; Jiang, C.; Hou, B.; Wang, Y.; Hao, C.; Wu, J. Carbon composite lignin-based adsorbents for the adsorption of dyes. Chemosphere 2018, 206, 587-596. [CrossRef] [PubMed]

7. Mohamed, A.; Yousef, S.; Abdelnaby, M.A.; Osman, T.A.; Hamawandi, B.; Toprak, M.S.; Muhammed, M.; Uheida, A. Photocatalytic degradation of organic dyes and enhanced mechanical properties of pan/cnts composite nanofibers. Sep. Purif. Technol. 2017, 182, 219-223. [CrossRef]

8. Wang, J.; Qin, L.; Lin, J.; Zhu, J.; Zhang, Y.; Liu, J.; Bruggen, B.V.D. Enzymatic construction of antibacterial ultrathin membranes for dyes removal. Chem. Eng. J. 2017, 323, 56-63. [CrossRef]

9. Oubagha, N.; Lemlikchi, W.; Sharrock, P.; Fiallo, M.; Mecherri, M.O. Hydroxyapatite precipitation with hydron blue dye. J. Environ. Manag. 2016, 203, 807-810. [CrossRef] [PubMed]

10. Baban, A.; Yediler, A.; Avaz, G.; Hostede, S.S. Biological and oxidative treatment of cotton textile dye-bath effluents by fixed and fluidized bed reactors. Bioresour. Technol. 2010, 101, 1147-1152. [CrossRef] [PubMed]

11. Ptaszkowska-Koniarz, M.; Goscianska, J.; Pietrzak, R. Removal of rhodamine b from water by modified carbon xerogels. Coll. Surf. A Physicochem. Eng. Asp. 2018, 543, 109-117. [CrossRef]

12. Shu, D.; Feng, F.; Han, H.; Ma, Z. Prominent adsorption performance of amino-functionalized ultra-light graphene aerogel for methyl orange and amaranth. Chem. Eng. J. 2017, 324, 1-9. [CrossRef]

13. Yagub, M.T.; Sen, T.K.; Afroze, S.; Ang, H.M. Dye and its removal from aqueous solution by adsorption: A review. Adv. Colloid Interface Sci. 2014, 209, 172-184. [CrossRef] [PubMed]

14. Ferralis, N. Probing mechanical properties of graphene with raman spectroscopy. J. Mater. Sci. 2010, 45, 5135-5149. [CrossRef]

15. Wang, H.; Hu, X.; Guo, Y.; Qiu, C.; Long, S.; Hao, D.; Cai, X.; Xu, W.; Wang, Y.; Liu, Y. Removal of copper ions by few-layered graphene oxide nanosheets from aqueous solutions: External influences and adsorption mechanisms. J. Chem. Technol. Biotechnol. 2018, 93, 2447-2455. [CrossRef]

16. Jiang, L.; Wang, J.; Liu, P.; Song, W.; He, B. Study of water adsorption on graphene edges. RSC Adv. 2018, 8, 11216-11221. [CrossRef]

17. Liu, Y.; Liu, H.; Chu, Y.; Cui, Y.; Hayasaka, T.; Dasaka, V.; Nguyen, L.; Lin, L. Defect-induced gas adsorption on graphene transistors. Adv. Mater. Interfaces 2018, 5, 1701640. [CrossRef] 
18. Stobiecka, M.; Chalupa, A. Modulation of plasmon-enhanced resonance energy transfer to gold nanoparticles by protein survivin channeled-shell gating. J. Phys. Chem. B 2015, 119, 13227-13235. [CrossRef] [PubMed]

19. Stobiecka, M. Novel plasmonic field-enhanced nanoassay for trace detection of proteins. Biosens. Bioelectron. 2014, 55, 379-385. [CrossRef] [PubMed]

20. Ratajczak, K.; Krazinski, B.; Kowalczyk, A.; Dworakowska, B.; Jakiela, S.; Stobiecka, M. Optical biosensing system for the detection of survivin mrna in colorectal cancer cells using a graphene oxide carrier-bound oligonucleotide molecular beacon. Nanomaterials 2018, 8, 510. [CrossRef] [PubMed]

21. Ratajczak, K.; Stobiecka, M. Ternary interactions and energy transfer between fluorescein isothiocyanate, adenosine triphosphate, and graphene oxide nanocarriers. J. Phys. Chem. B 2017, 121, 6822-6830. [CrossRef] [PubMed]

22. Stobiecka, M.; Dworakowska, B.; Jakiela, S.; Lukasiak, A.; Chalupa, A.; Zembrzycki, K. Sensing of survivin mrna in malignant astrocytes using graphene oxide nanocarrier-supported oligonucleotide molecular beacons. Sens. Actuators B Chem. 2016, 235, 136-145. [CrossRef]

23. Lerf, A.; He, H.; Forster, M.; Klinowski, J. Structure of graphite oxide revisitedll. J. Phys. Chem. B 1998, 102, 4477-4482. [CrossRef]

24. Cruzsilva, R.; Endo, M.; Terrones, M. Graphene oxide films, fibers, and membranes. Nanotechnol. Rev. 2016, 5. [CrossRef]

25. Seabra, A.B.; Paula, A.J.; De, R.L.; Alves, O.L.; Durán, N. Nanotoxicity of graphene and graphene oxide. Chem. Res. Toxicol. 2014, 27, 159-168. [CrossRef] [PubMed]

26. Golkaram, M.; Van Duin, A.C.T. Revealing graphene oxide toxicity mechanisms: A reactive molecular dynamics study. Mater. Discov. 2015, 1, 54-62. [CrossRef]

27. Guo, X.; Mei, N. Assessment of the toxic potential of graphene family nanomaterials. J. Food Drug Anal. 2014, 22, 105-115. [CrossRef] [PubMed]

28. Dai, J.; Huang, T.; Tian, S.Q.; Xiao, Y.J.; Yang, J.H.; Zhang, N.; Wang, Y.; Zhou, Z.W. High structure stability and outstanding adsorption performance of graphene oxide aerogel supported by polyvinyl alcohol for waste water treatment. Mater. Des. 2016, 107, 187-197. [CrossRef]

29. Huang, T.; Dai, J.; Yang, J.H.; Zhang, N.; Wang, Y.; Zhou, Z.W. Polydopamine coated graphene oxide aerogels and their ultrahigh adsorption ability. Diam. Relat. Mater. 2018, 86, 117-127. [CrossRef]

30. Wei, X.; Huang, T.; Yang, J.H.; Zhang, N.; Wang, Y.; Zhou, Z.W. Green synthesis of hybrid graphene oxide/microcrystalline cellulose aerogels and their use as superabsorbents. J. Hazard. Mater. 2017, 335, $28-38$. [CrossRef] [PubMed]

31. Yang, X.; Li, Y.; Du, Q.; Sun, J.; Chen, L.; Hu, S.; Wang, Z.; Xia, Y.; Xia, L. Highly effective removal of basic fuchsin from aqueous solutions by anionic polyacrylamide/graphene oxide aerogels. J. Colloid Interface Sci. 2015, 453, 107-114. [CrossRef] [PubMed]

32. Liu, S.; Yao, F.; Oderinde, O.; Zhang, Z.; Fu, G. Green synthesis of oriented xanthan gum-graphene oxide hybrid aerogels for water purification. Carbohydr. Polym. 2017, 174, 392-399. [CrossRef] [PubMed]

33. Liang, Q.; Luo, H.; Geng, J.; Chen, J. Facile one-pot preparation of nitrogen-doped ultra-light graphene oxide aerogel and its prominent adsorption performance of cr(vi). Chem. Eng. J. 2017, 338, 62-71. [CrossRef]

34. Li, Y.; Li, L.; Chen, T.; Duan, T.; Yao, W.; Zheng, K.; Dai, L.; Zhu, W. Bioassembly of fungal hypha/graphene oxide aerogel as high performance adsorbents for U(VI) removal. Chem. Eng. J. 2018, 347, 407-414. [CrossRef]

35. Mi, X.; Huang, G.; Xie, W.; Wang, W.; Liu, Y.; Gao, J. Preparation of graphene oxide aerogel and its adsorption for $\mathrm{Cu}^{2+}$ ions. Carbon 2012, 50, 4856-4864. [CrossRef]

36. Wang, J.; Yao, Q.; Sheng, C.; Jin, C.; Sun, Q. One step preparation of graphene oxide/cellulose nanofibril hybrid aerogel for adsorptive removal of four kinds of antibiotics. J. Nanomater. 2017, 2017, 5150613. [CrossRef]

37. Yao, Q.; Fan, B.; Ye, X.; Jin, C.; Sun, Q.; Sheng, C. 3D assembly based on 2D structure of cellulose nanofibril/graphene oxide hybrid aerogel for adsorptive removal of antibiotics in water. Sci. Rep. 2017, 7, 45914. [CrossRef] [PubMed]

38. Soleimani, K.; Tehrani, A.D.; Adeli, M. Bioconjugated graphene oxide hydrogel as an effective adsorbent for cationic dyes removal. Ecotoxicol. Environ. Saf. 2018, 147, 34-42. [CrossRef] [PubMed]

39. Wan, C.; Li, J. Graphene oxide/cellulose aerogels nanocomposite: Preparation, pyrolysis, and application for electromagnetic interference shielding. Carbohydr. Polym. 2016, 150, 172-179. [CrossRef] [PubMed] 
40. Yadav, M.; Rhee, K.; Jung, I.; Park, S. Eco-friendly synthesis, characterization and properties of a sodium carboxymethyl cellulose/graphene oxide nanocomposite film. Cellulose 2013, 20, 687-698. [CrossRef]

41. Begum, H.A.; Mahbub, M.K.B. Effectiveness of carboxymethyl cellulose for the removal of methylene blue from aqueous solution. Dhaka Univ. J. Sci. 2013, 61, 2. [CrossRef]

42. Layek, R.K.; Kundu, A.; Nandi, A.K. High-performance nanocomposites of sodium carboxymethylcellulose and graphene oxide. Macromol. Mater. Eng. 2013, 298, 1166-1175. [CrossRef]

43. Zhang, Y.; Liu, Y.; Wang, X.; Sun, Z.; Ma, J.; Wu, T.; Xing, F.; Gao, J. Porous graphene oxide/carboxymethyl cellulose monoliths, with high metal ion adsorption. Carbohydr. Polym. 2014, 101, 392-400. [CrossRef] [PubMed]

44. Liu, J.; Chu, H.; Wei, H.; Zhu, H.; Wang, G.; Zhu, J.; He, J. Facile fabrication of carboxymethyl cellulose sodium/graphene oxide hydrogel microparticles for water purification. RSC Adv. 2016, 6, 50061-50069. [CrossRef]

45. Varaprasad, K.; Jayaramudu, T.; Sadiku, E.R. Removal of dye by carboxymethyl cellulose, acrylamide and graphene oxide via a free radical polymerization process. Carbohydr. Polym. 2017, 164, 186-194. [CrossRef] [PubMed]

46. Xing, B.; Zhang, C.; Cao, Y.; Huang, G.; Liu, Q.; Zhang, C.; Chen, Z.; Yi, G.; Chen, L.; Yu, J. Preparation of synthetic graphite from bituminous coal as anode materials for high performance lithium-ion batteries. Fuel Process. Technol. 2018, 172, 162-171. [CrossRef]

47. Hu, H.; Zhao, Z.; Wan, W.; Gogotsi, Y.; Qiu, J. Ultralight and highly compressible graphene aerogels. Adv. Mater. 2013, 25, 2219-2223. [CrossRef] [PubMed]

48. Kota, M.; Yu, X.; Yeon, S.H.; Cheong, H.W.; Park, H.S. Ice-templated three dimensional nitrogen doped graphene for enhanced supercapacitor performance. J. Power Source 2016, 303, 372-378. [CrossRef]

49. Ferrari, A.C.; Robertson, J. Interpretation of raman spectra of disordered and amorphous carbon. Phys. Rev. $B$ Cond. Matter 2000, 61, 14095-14107. [CrossRef]

50. Ge, X.; Shan, Y.; Wu, L.; Mu, X.; Peng, H.; Jiang, Y. High-strength and morphology-controlled aerogel based on carboxymethyl cellulose and graphene oxide. Carbohydr. Polym. 2018, 197, 277-283. [CrossRef] [PubMed]

51. Zhou, G.; Wang, D.W.; Yin, L.C.; Li, N.; Li, F.; Cheng, H.M. Oxygen bridges between nio nanosheets and graphene for improvement of lithium storage. ACS Nano 2012, 6, 3214-3223. [CrossRef] [PubMed]

52. Quan, Z.; Zhao, Z.; Zhang, Y.; Bo, M.; Zhou, A.; Qiu, J. Graphene sheets from graphitized anthracite coal: Preparation, decoration, and application. Energy Fuels 2012, 26, 5186-5192.

53. El Achaby, M.; El Miri, N.; Snik, A.; Zahouily, M.; Abdelouahdi, K.; Fihri, A.; Barakat, A.; Solhy, A. Mechanically strong nanocomposite films based on highly filled carboxymethyl cellulose with graphene oxide. J. Appl. Polym. Sci. 2015, 133. [CrossRef]

54. Rao, Z.; Ge, H.; Liu, L.; Zhu, C.; Min, L.; Liu, M.; Fan, L.; Li, D. Carboxymethyl cellulose modified graphene oxide as ph-sensitive drug delivery system. Int. J. Biol. Macromol. 2017, 107, 1184-1192. [CrossRef] [PubMed]

55. Kang, W.; Lin, B.; Huang, G.; Zhang, C.; Hou, W.; Yao, Y.; Xu, B.; Xing, B. Nitrogen and oxygen co-doped porous carbon for high performance supercapacitors. J. Mater. Sci. Mater. Electron. 2018, 29, 3340-3347. [CrossRef]

56. Compton, O.C.; Dikin, D.A.; Putz, K.W.; Brinson, L.C.; Nguyen, S.T. Electrically conductive "alkylated" graphene paper via chemical reduction of amine-functionalized graphene oxide paper. Adv. Mater. 2010, 22, 892-896. [CrossRef] [PubMed]

57. Jing, X.; Li, W.; Zhu, Y. Decontamination of bisphenol a from aqueous solution by graphene adsorption. Langmuir 2012, 28, 8418-8425.

58. Gerçel, Ö.; Gerçel, H.F. Adsorption of lead(ii) ions from aqueous solutions by activated carbon prepared from biomass plant material of euphorbia rigida. Chem. Eng. J. 2007, 132, 289-297. [CrossRef]

59. Doğan, M.; Alkan, M.; Demirbaş, Ö.; Özdemir, Y.; Özmetin, C. Adsorption kinetics of maxilon blue grl onto sepiolite from aqueous solutions. Chem. Eng. J. 2006, 124, 89-101. [CrossRef]

60. Ho, Y.S. Second-order kinetic model for the sorption of cadmium onto tree fern: A comparison of linear and non-linear methods. Water Res. 2006, 40, 119-125. [CrossRef] [PubMed]

61. Langmuir, I. The adsorption of gases on plane surfaces of glass, mica and platinum. J. Am. Chem. Soc. 1918, 40, 1361-1403. [CrossRef] 
62. Neghlani, P.K.; Rafizadeh, M.; Taromi, F.A. Preparation of aminated-polyacrylonitrile nanofiber membranes for the adsorption of metal ions: Comparison with microfibers. J. Hazard. Mater. 2011, 186, 182-189. [CrossRef] [PubMed]

63. Liu, C.; Liu, H.; Xu, A.; Tang, K.; Huang, Y.; Lu, C. In situ reduced and assembled three-dimensional graphene aerogel for efficient dye removal. J. Alloy. Compd. 2017, 714, 522-529. [CrossRef] 